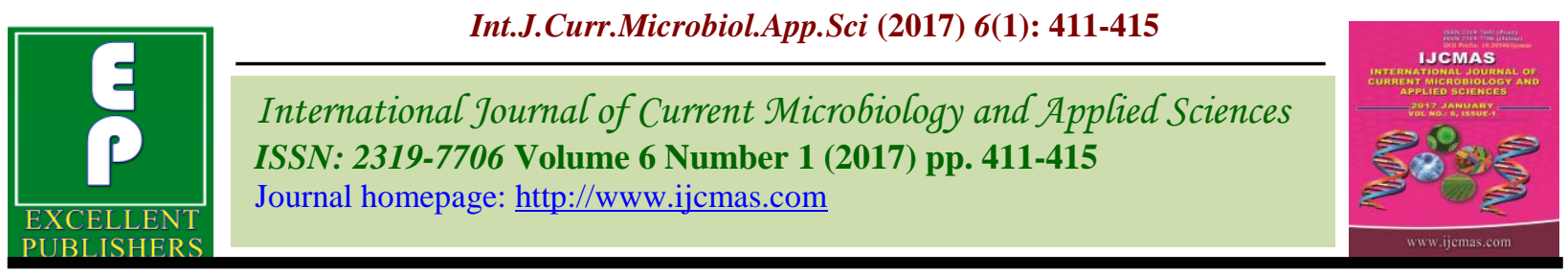

Original Research Article

http://dx.doi.org/10.20546/ijcmas.2017.601.049

\title{
A Study by Double Disc Diffusion (DDDT) Method to Compare Ceftazidime + Clavulanic Acid and Cefotaxime + Clavulanic Acid for Detection of Extended Spectrum B- Lactamase among Escherichia coli and Klebsiella pneumoniaee in Urinary Isolates
}

\author{
R. Sujatha*, Anil Kumar and Vikas Mishra \\ Department of Microbiology, Rama Medical College, Kanpur, India \\ *Corresponding author
}

\begin{abstract}
Keywords
Extended-spectrum $\beta$-lactamase,

Phenotypic detection, double disc diffusion test.

Article Info

Accepted:

23 December 2016

Available Online:

10 January 2017 and Klebsiella pneumoniae in urinary isolates. This study was carried out in the Department of Microbiology, Rama Medical College, Kanpur(U.P), India from November 2015 to August 2016. Patients of all ages and genders were taken as study population. Lactose fermenting gram negative bacilli(GNB) were analyzed and routine susceptibility testing was performed. Screening test for ESBL production was done by two disc diffusion methods Ceftazidime and Ceftazidime+Clavulinic acid(CAZ/CAZC) and Cefotaxime and Cefotaxime+ Clavulinic acid (CTX/CTXC). In our study, 576 urine samples have been collected, from them 369 uropathogens were isolated 102 (17.07\%) Escherichia coli, 66 (11.45\%) Klebsiella pneumoniae and 201 others(34.89\%) (including Staphylococcus aureus, CONS, Proteus species, Pseudomonas aeruginosa, Acinetobacter species and candida species) respectively. The prevalence of ESBL producing Escherichia coli and Klebsiella pneumoniae in our study is $30.39 \%$ and $36.36 \%$ respectively. Of the 65 Escherichia coli and 41 Klebsiella pneumoniae Screned For ESBL . 46 isolate were detected by combined disc method. The use of ceftazidime $(30 \mu \mathrm{g})$ and ceftazidime + clavulanic $\operatorname{acid}(30 \mu \mathrm{g} / 10 \mu \mathrm{g})$ detected 46 isolates as ESBL positive as compared to cefotaxime $(30 \mu \mathrm{g})$ and cefotaxime + clavulanic acid(30 $\mu \mathrm{g} / 10 \mu \mathrm{g})$ which detected 33 isolates as ESBL positive. The use of ceftazidime $(30 \mu \mathrm{g})$ and ceftazidime + clavulanic acid(30 $\mu \mathrm{g} / 10 \mu \mathrm{g})$ DDDT phenotypic methods are useful diagnostic tool for detection of ESBL in gram negative bacilli..
\end{abstract}

A B S T R A C T

The detection of extended- spectrum $\beta$-lactamase (ESBL) producing bacteria is important for infection control and epidemiological surveillance. The purpose of the present study was to compare two phenotypic methods for detection of ESBL positive Escherichia coli

\section{Introduction}

Extended spectrum $\beta$-Lactamases (ESBL) are enzymes produced by pathogens belonging to Enterobacteriaceae, most commonly Escherichia coli and Klebsiella pneumoniae (Kenneth et al., 2010).
They cause serious infections and have high mortality rates. Multidrug-resistant ESBL E. coli (CTX-M enzyme type) has emerged as an important cause of UTI (Gisele et al., 2010). ESBL strains are capable of efficiently hydrolyzing many beta-lactam antibiotics 
including cephalosporins and monobactams. $\beta$ lactamase inhibitors (clavulanic acid, sulbactam, and tazobactam) generally inhibit ESBL producing strains (Rupp, 2003). It is increasingly being reported that they are acquiring a transmissible form of antibiotic resistance. This indicate that penicillins and cephalosporins which have been used for many years are no more effective against ESBL positive (Duttaroy et al., 2005). Nosocomial outbreaks of infections caused by ESBL-producing gram-negative bacteria have also been reported, which are mainly the result of extensive and inappropriate use of third-generation cephalosporins. The major risk factors implicated are long-term exposure to antibiotics, prolonged ICU stay, nursing home residency, severe illness, instrumentation, or catheterization (Kumar et al., 2006).

The aim of this study is to evaluate the utility of ceftazidime+clavulanic acid as a better method than cefotaxime $(30 \mu \mathrm{g})$ and cefotaxime + clavulanic acid $(30 \mu \mathrm{g} / 10 \mu \mathrm{g})$ for detection of extended spectrum beta lactamases (ESBL) in E.coli and Klebsiella pneumoniaee in urinary isolates.

\section{Materials and Methods}

The present study was conducted in the Department of Microbiology, Rama Medical College, Kanpur over a period of 10 months (November 2015 to August 2016). A total of 576 urine samples were obtained from various clinical departments including OPD and IPD of all age groups including both the genders. All samples were routinely cultured on CLED agar plates at $37^{\circ} \mathrm{C}$ aerobically for 18 hours and gram negative isolates were further characterized by standard biochemical tests. Isolates were screened for ESBL production by using disc diffusion test on Muller Hinton agar according to CLSI guidelines, 2016. ${ }^{[16]}$
Isolates showing inhibition zone size of $\geq 22 \mathrm{~mm}$ with ceftazidime $(30 \mu \mathrm{g}), \geq 25 \mathrm{~mm}$ with ceftriaxone $(30 \mu \mathrm{g}), \geq 27 \mathrm{~mm}$ with cefotaxime $(30 \mu \mathrm{g}), \geq 27 \mathrm{~mm}$ with aztreonam $(30 \mu \mathrm{g})$ were suspected for ESBL production. All screening test positive isolates were further confirmed by Phenotypic confirmatory test for ESBL producers by double disc diffusion test (DDDT) and Double disc diffusion test (DDDT) was performed by two methods which were ceftazidime and ceftazidime plus clavulinic acid (CAZ/CAZC) and cefotaxime and cefotaxime plus clavulinic Acid (CTX/CTXC). E. coli ATCC 25922 was used as negative control and Klebsiella pneumoniaee ATCC 700603 used as positive control.

\section{Results and Discussion}

In our study, 576 urine samples have been collected, from them 369 uropathogens were isolated 102 Escherichia coli, 66 Klebsiella pneumoniaee and 201 other isolates (including Staphylococcus aureus, CONS, Proteus species, Pseudomonas aeruginosa, Acinetobacter species and candida) respectively.[Table-1] The prevalence of ESBL producing Escherichia coli and Klebsiella pneumoniaee in our study, is $30.39 \%$ and $36.36 \%$ respectively. The proportion of ESBL was found higher in Klebsiella pneumoniaee.[Table-2] The ESBL frequencies varied from $66.7 \%$ in India, $54.7 \%$ - $61 \%$ in Turkey (Gaurav) $41 \%$ in United Arab Emirates, $31.7 \%$ in Kuwait and $72.1 \%$ in Iran but was found lower in America and Europe (Kumar et al., 2006).

The overall prevalence of ESBL producers was found to vary greatly in different geographical areas and in different parts in India. In our study, the rate of ESBLsproducer isolates was higher than that reported from Nagpur, Aligarh respectively in 2004, 2009 and 2012 (Lal et al., 2007; 
Shoorashetty et al., 2011; Tankhiwale et al., 2004). Whereas still lower than the rate reported in a study from Delhi, Jaipur and
Maharashtra respectively in 2003, 2014 and 2016 in urinary isolates.

Table.1 Distribution of organisms from the urine samples

\begin{tabular}{|c|l|l|l|c|}
\hline Total urine sample & E.coli & $\begin{array}{l}\text { Klebsiella } \\
\text { pneumoniaee }\end{array}$ & Others & $\begin{array}{c}\text { Total } \\
\text { Urinary } \\
\text { pathogens (\%) }\end{array}$ \\
\hline 576 & $102(17.07 \%)$ & $66(11.45 \%)$ & $201(34.89 \%)$ & $369(64.06 \%)$ \\
\hline
\end{tabular}

Table.2 ESBL screening method

\begin{tabular}{|l|c|c|}
\hline \multicolumn{1}{|c|}{ Organisms } & Positive & Negative \\
\hline Escherichia coli & 65 & 37 \\
\hline Klebsiella pneumoniaee & 41 & 25 \\
\hline
\end{tabular}

Table.3 Comparison between different disk diffusion methods to detect ESBL

\begin{tabular}{|c|l|c|c|c|}
\hline $\begin{array}{c}\text { Total } \\
\text { isolates }\end{array}$ & Organisms & $\begin{array}{c}\text { Screening } \\
\text { test } \\
\text { positive }\end{array}$ & $\begin{array}{c}\text { Ceftazidime and } \\
\text { Ceftazidime with } \\
\text { clavulanic acid }\end{array}$ & $\begin{array}{c}\text { Cefotaxime and } \\
\text { Cefotaxime with } \\
\text { clavulanic acid }\end{array}$ \\
\hline 102 & Escherichia coli & 65 & 27 & 18 \\
\hline 66 & $\begin{array}{l}\text { Klebsiella } \\
\text { pneumoniae }\end{array}$ & 41 & 19 & 15 \\
\hline
\end{tabular}

Fig.1 showing ESBL production by phenotypic confirmatory method (by Double Disk Diffusion test)

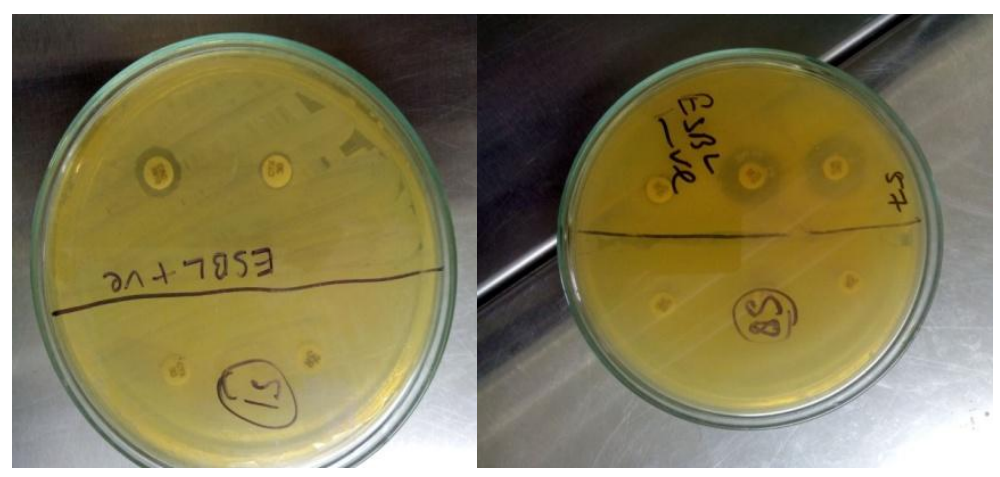

This may be due to differences in the type and volume of consumption of antibiotics and differences in the year of collection of isolates. However, it reflects the increase in the prevalence of ESBL producers in India.
As in other studies, the majority of ESBLproducing isolates were recovered from urine. Of the 65 Escherichia coli and 41 Klebsiella pneumoniae isolated by ESBL screening test among them, a total of 46 ESBL were 
detected by combined disc method. [Table-3] The use of ceftazidime $(30 \mu \mathrm{g})$ and ceftazidime + clavulanic acid $(30 \mu \mathrm{g} / 10 \mu \mathrm{g})$ detected 46 isolates as ESBL positive as compared to cefotaxime $(30 \mu \mathrm{g})$ and cefotaxime + clavulanic acid $(30 \mu \mathrm{g} / 10 \mu \mathrm{g})$ [Table-3] [figure-1] which detected 33 isolates as ESBL positive. The result of our study shows similar findings with those who reported $45.2 \%$ isolates were ESBL positive by using ceftazidime and ceftazidime + clavulanic acid as compared to cefotaxime and cefotaxime + clavulanic acid which detected $36 \%$ isolates as ESBL positive.

In conclusion routine use of both DDDT is useful for the detection of ESBL in clinical samples. The use of Ceftazidime and Ceftazidime with clavulanic acid was found to the better method for detection of ESBL producing bacteria in our study especially in urine isolates (E.coli and Klebsiella pneumoniaee).

\section{References}

Ben-Ami, R., Rodríguez-Baño, J., Arslan, H., Pitout, J.D., Quentin, C., et al. A multinational survey of risk factors for infection with extended-spectrum betalactamase- producing enterobacteriaceae in nonhospitalized patients, Clin. Infect. Dis., 49: 682-690.

CLSI. 2016. Performance Standards for Antimicrobial Susceptibility Testing, sTwenty-Fourth Informational Supplement. CLSI document M100S24. Wayne, PA: Clinical and Laboratory Standards Institute.

Duttaroy, B., Mehta, S. et al. 2005. Extended spectrum $\beta$ lactamases (ESBL) in clinical isolates of Klebsiella pneumoniaee and Escherichia coli. Indian J. Pathol. Microbiol., 48:45-8.

Gaurav Dalela et al. 2016. Prevalence of Extended Spectrum Beta lactamase producers among gram negative bacilli from various clinical isolates in a tertiary Care Hospital at Jhalawar, Rajiasthan, India. India J. Clin. Diag. Res., 6(2):182-187.

Gisele, P., David, R., Jana, N., Allison, M., Vivian, L., Baldwin, T., et al. 2010. High Prevalence of ST131 Isolates Producing CTX-M-15 and CTX-M-14 among extended-spectrum- $\beta$-lactamaseproducing Escherichia coli isolates from Canada. Antimicrob. Agents Chemother., 54: 1327-1330

Kenneth, S., Thomson, et al. 2010. Extendedspectrum- $\beta$-lactamase, AmpC, and Carbapenemase, J. Clin. Microbiol., 48: 1019-102.

Kumar, M.S., Lakshmi, V., Rajagopalan, R. et al. 2006. Occurrence of extended spectrum $\quad \beta$ lactamases among Enterobacteriaceae spp. isolated at a tertiary care institute. Indian J. Med. Microbiol., 24:208-210.

Lal, P., Kapil, A., Das, B.K., and Sood, S. et al. Occurence of TEM and SHV gene in extended spectrum beta lactamases (ESBLs) producing Klebsiella spp.isolated from a tertiary care hospital, Indian J. Med., 125: 173-178.

Mita, D.W., Anuradha, K., Venkatesha, D. 2013. et al. Phenotypic detection of ESBL and MBL in clinical isolates of Enterobacteriaceae. Int. J. Curr. Res. Aca. Rev., 1(3): 89-95

Mohanty, S., Meera Sharma \& Pallab Ray, et al. 2010. Detection of TEM \& SHV genes in Escherichia coli \& Klebsiella pneumoniaee isolates in a tertiary care hospital, Indian J. Med. Res., 132: 332336.

Rupp, M.E., Fey, P.D. et al. 2003. Extendedspectrum $\beta$-lactamase(ESBL)-producing Enterobacteriaceae: considerations for diagnosis, prevention and drug treatment, Drugs, 63: 353-365. 
Shipra Agarwal, et al. 2016. Int. J. Curr. Microbiol. Appl. Sci., 2: 267-271.

Shoorashetty, R.M., Nagarathnamma, T., Prathibha, J. et al. 2011. Comparison of the boronic acid disk potentiation test and cefepime-clavulanic acid method for the detection of ESBL among AmpC-producing Enterobacteriaceae. Ind. J. Med. Microbiol., 29: 297-301.

Tankhiwale, S.S., Jalgaonkar, S.V., Ahamad, S., Hassani, U. et al. 2004. Evaluation of extended spectrum beta lactamase in urinary isolates. Indian J. med. Res., 120: 553-556.

Taslim yesmin, et al. 2016. Immunol. infectious dis., 3(2):19-23.

Upadhyay, S., Sen, M.R., Bhattacharjee, A. 2016. Presence of different beta lactamase, Int. J. Curr. Microbiol. App. Sci., 5(2): 267-271.

\section{How to cite this article:}

Sujatha, R., Anil Kumar, Vikas Mishra. 2017. A Study by Double Disc Diffusion (DDDT) Method to Compare Ceftazidime + Clavulanic Acid and Cefotaxime + Clavulanic Acid for Detection of Extended Spectrum B- Lactamase among Escherichia coli and Klebsiella pneumoniaee in Urinary Isolates. Int.J.Curr.Microbiol.App.Sci. 6(1): 411-415. doi: http://dx.doi.org/10.20546/ijcmas.2017.601.049 